\title{
Comparison between elderly inpatient fallers with and without dementia
}

Si Ching $\underline{\operatorname{Lim}}^{1}$, MBChB, MRCP, Kaysar Mamun ${ }^{2}$, ABIM, ABGM, Jim KH $\underline{\operatorname{Lim}}^{1}$, MBBS, MRCP

INTRODUCTION This study aimed to examine the various factors associated with inpatient falls among patients with and without dementia in a hospital setting.

METHODS This was a retrospective one-year study using data collected from Singapore General Hospital's electronic reporting system for inpatient falls.

RESULTS In the study period, 298 patients aged $\geq 65$ years fell during their hospital stay. The majority of the patients ( $n=248$ ) did not have dementia. In our study, fallers with dementia were more likely to use ambulatory aids, be visually impaired and have urinary incontinence. More patients with dementia than those without had a history of previous falls, and were placed on fall precaution with restricted freedom of movement, which at times, included restraints. However, the difference between patients who were put on restraints and those who were allowed to move freely was not statistically significant. The majority of falls in both groups occurred at the bedside. We found that fallers without dementia were more likely to fall during the morning shift, whereas fallers with dementia were more likely to fall during the night shift. Fallers with dementia were more likely to be confused at the time of the fall. CONCLUSION In our study, we found that fallers with dementia were more likely to have visual impairment, have urinary incontinence, use walking aids, and to be confused and physically restrained at the time of the fall. The fallers without dementia in our study may have undiagnosed dementia.

Keywords: delirium, dementia, inpatient falls, restraint use, urinary incontinence

\section{INTRODUCTION}

Falls among elderly inpatients over the age of 65 is a common problem that is associated with considerable morbidity, functional decline, premature institutionalisation and mortality. ${ }^{(1-4)}$ About $35 \%-40 \%$ of community-dwelling elderly fall every year, and among them, 50\% will have recurrent falls. The annual incidence of falls among patients with dementia is even higher at $40 \%-60 \%{ }^{(5,6)}$ Elderly persons with dementia are found to be at a higher risk of sustaining serious injuries, with $25 \%$ of fallers with dementia sustaining a fracture; this figure is three times the age-adjusted fracture incidence of elderly fallers without dementia. ${ }^{(78)}$ Compared to elderly fallers without dementia, elderly fallers with dementia have a poorer prognosis, a lower likelihood of full recovery, a higher risk of institutionalisation (up to five times higher), and a much higher mortality at six months after a femoral neck fracture. ${ }^{(6,9)}$ Compared to those in the community, fall rates among the institutionalised elderly are three times higher, and these falls are associated with a higher rate of injury requiring hospitalisation. ${ }^{(10)}$

Despite the presence of close monitoring, the hospital setting is not a safe place for the elderly. Falls account for at least $40 \%$ of all accidents in a hospital setting. ${ }^{(11)}$ The risk of hip fracture was found to be 11 times higher among inhospital patients than those dwelling in the community. ${ }^{(12)}$ In our study, we found that the majority of falls in the hospital occurred during the first week of hospitalisation. Several risk factors for falls in the hospital setting have been implicated, and these include: strange environment with unfamiliar danger zones, dizziness and balance problems, difficulties with transfer or ambulation, delirium, visual impairment, polypharmacy and inappropriate use of medication, and incontinence and increased toileting frequency. ${ }^{(2-4,13,14)}$ Another evident risk factor for falls is dementia. Hospitalisation may lead to delirium in a patient with dementia, which may put the patient at a higher risk of falls in an acute hospital setting. Unfortunately, there is no comparative data available on falls in patients with dementia and those without dementia in acute hospital settings. Therefore, we decided to conduct a retrospective data analysis in Singapore General Hospital, Singapore, to ascertain the possible risk factors that may predict falls in hospitalised patients with dementia.

\section{METHODS}

Falls in Singapore General Hospital are a closely monitored, reportable adverse event. All falls are reported and inputted electronically into the hospital's falls database. On admission, nurses assess the fall risk of all patients and initiate fall precautions if indicated. Retrospective data analysis was performed for patients aged $\geq 65$ years who fell during their hospital stay and whose fall was reported in the hospital database from July 2011 to June 2012. Information obtained from the case notes included: (a) demographic information; (b) assessment of fall risk on admission; (c) circumstance and time of fall;

${ }^{1}$ Department of Geriatric Medicine, Changi General Hospital, ${ }^{2}$ Department of Geriatric Medicine, Singapore General Hospital, Singapore

Correspondence: Dr Lim Si Ching, Consultant, Department of Geriatric Medicine, Changi General Hospital, 2 Simei Street 3 , Singapore 529889. si_ching_lim@cgh.com.sg 
Table I. Demographics of patients who fell during hospitalisation $(n=298)$.

\begin{tabular}{|c|c|c|c|}
\hline \multirow[t]{2}{*}{ Variable } & \multicolumn{2}{|c|}{ No. of patients (\%) } & \multirow[t]{2}{*}{ p-value } \\
\hline & Without dementia $(n=248)$ & With dementia $(n=50)$ & \\
\hline Age $^{*}$ (yrs) & $75.75(65-96)$ & $75.96(66-94)$ & 0.813 \\
\hline No. of medical problems* & $4.94(0-12)$ & $4.88(1-8)$ & 0.778 \\
\hline Length of stay* (days) & $15.92(2-74)$ & $15.90(3-52)$ & 0.991 \\
\hline Morse scale score* & $40.21(0-95)$ & $48.60(10-100)$ & 0.028 \\
\hline $\begin{array}{l}\text { Gender }^{+} \\
\text {Male } \\
\text { Female }\end{array}$ & $\begin{array}{r}155(62.5) \\
93(37.5)\end{array}$ & $\begin{array}{l}25(50.0) \\
25(50.0)\end{array}$ & 0.114 \\
\hline $\begin{array}{l}\text { Race }^{*} \\
\text { Chinese } \\
\text { Malay } \\
\text { Indian } \\
\text { Others }\end{array}$ & $\begin{aligned} 209 & (84.3) \\
9 & (3.6) \\
24 & (9.7) \\
6 & (2.4)\end{aligned}$ & $\begin{array}{c}44(88.0) \\
4(8.0) \\
0(0.0) \\
2(4.0)\end{array}$ & 0.068 \\
\hline $\begin{array}{l}\text { Admitted from }{ }^{+} \\
\text {A\&E } \\
\text { SOC }\end{array}$ & $\begin{array}{c}225(90.7) \\
23(9.3)\end{array}$ & $\begin{array}{c}48(96.0) \\
2(4.0)\end{array}$ & 0.276 \\
\hline $\begin{array}{l}\text { Admitted to* } \\
\text { Medical } \\
\text { Surgical } \\
\text { Others }\end{array}$ & $\begin{aligned} 212 & (85.5) \\
35 & (14.1) \\
1 & (0.4)\end{aligned}$ & $\begin{array}{c}34(68.0) \\
16(32.0) \\
0(0.0)\end{array}$ & 0.009 \\
\hline
\end{tabular}

${ }^{*}$ Data is presented as mean (range), and was analysed using $t$-test. ${ }^{\dagger}$ Data was analysed using Fisher's exact test. ${ }^{\ddagger}$ Data was analysed using chi-square test. A\&E: accident and emergency; SOC: specialist outpatient clinic

(d) cognitive status; and (e) presence of confusion at the time of fall. Since this was a retrospective study, no formal assessment of dementia or confusion by geriatricians was done. Instead, each patient's respective diagnosis was taken as that documented in the case notes. In the present study, fallers with dementia were compared against those without dementia to ascertain unique risk factors that may predict falls in hospitalised elderly patients with dementia. For the purpose of this study, a fall was defined as having occurred if an individual came to rest involuntarily on a surface lower than his/her original station. ${ }^{(15)}$ Data analysis was performed using the Statistical Package for the Social Sciences (SPSS Inc, Chicago, IL, USA). This study was approved by the hospital's ethics committee.

\section{RESULTS}

Between July 2011 and June 2012, a total of 298 elderly patients, defined as aged $\geq 65$ years, fell during their hospital stay. At the time of admission, the majority ( $n=248$ ) of the patients were not noted to have dementia. The demographic data and fall risk profile of both groups of fallers (i.e. those with dementia and those without) are described in Table I.

Comparing between the two groups of fallers in our cohort, we found no significant differences in age, gender, race and source of admission. However, a larger proportion of fallers with dementia was admitted to the surgical department than those without dementia. This may be because a large number of elderly fallers with head injuries are routinely admitted to the Department of General Surgery.

Table II compares the fall risk factors of fallers with and without dementia at the time of admission. Comparing between fallers with dementia and those without, we found that the former group of patients was more likely to use ambulatory aids $(36.0 \%$ vs. $22.6 \%)$, have urinary incontinence $(30.0 \%$ vs. $17.3 \%$ ) and have visual impairment (38.0\% vs. $18.1 \%)$. More patients with dementia than those without had a history of falls $(46.0 \%$ vs. $31.9 \%)$, were placed on fall precaution $(98.0 \%$ vs. $91.9 \%$ ), had restricted freedom of movement (i.e. rest in bed and toilet, and complete rest in bed [including restraint]; $26.0 \%$ vs. $20.6 \%$, and were put on body restraints $(14.0 \%$ vs $7.7 \%$ ) before the fall. However, these differences were not statistically significant.

Table III summarises the circumstances and consequences of the falls in the present study. The majority of falls in both groups occurred within the first week of hospitalisation and at the bedside while they were getting up from their beds. While fallers without dementia were more likely than those with dementia to fall during the morning shift $(61.3 \%$ vs. $38.0 \%$, fallers with dementia were more likely than those without to fall during the night shift $(40.0 \%$ vs. $23.8 \%)$ and to be confused at the time of the fall $(94.0 \%$ vs $27.4 \%)$. Most falls did not lead to major injuries.

\section{DISCUSSION}

Inpatient falls are common but serious events that may lead to negative consequences such as injuries, prolonged hospital stay, delayed rehabilitation and possible litigation. In our study, fallers with dementia were more likely to be using ambulatory aids at the time of admission. This suggests that these patients had poor or unsafe gait, which required the use of ambulatory aids to reduce fall risk. Gait and balance impairments are common among the elderly, but for elderly persons with dementia, these impairments are more severe. The walking speed of elderly persons with dementia would tend to be slower, with reduced step frequency and step length, and 
Table II. Fall risk on admission.

\begin{tabular}{|c|c|c|c|}
\hline \multirow[t]{2}{*}{ Risk factors } & \multicolumn{2}{|c|}{ No. of patients (\%) } & \multirow[t]{2}{*}{ p-value } \\
\hline & Without dementia $(n=248)$ & With dementia $(n=50)$ & \\
\hline History of falls* & & & 0.072 \\
\hline Yes & 79 (31.9) & $23(46.0)$ & \\
\hline No & $169(68.1)$ & $27(54.0)$ & \\
\hline Use of ambulatory aid* & & & 0.050 \\
\hline Yes & $56(22.6)$ & $18(36.0)$ & \\
\hline No & $192(77.4)$ & $32(64.0)$ & \\
\hline Type of ambulatory aid used ${ }^{+}$ & & & 0.320 \\
\hline Walking stick & $38(15.3)$ & $15(30.0)$ & \\
\hline Quad stick & $4(1.6)$ & $1(2.0)$ & \\
\hline Walking frame & $14(5.6)$ & $2(4.0)$ & \\
\hline None & $192(77.4)$ & $32(64.0)$ & \\
\hline Premorbid function status ${ }^{+}$ & & & 0.474 \\
\hline Community-dwelling and ambulatory & $83(33.5)$ & $12(24.0)$ & \\
\hline Walk with assistance & $82(33.1)$ & $20(40.0)$ & \\
\hline Wheelchair-bound but independent & $50(20.2)$ & $10(20.0)$ & \\
\hline Chairbound & $28(11.3)$ & $8(16.0)$ & \\
\hline Bedbound & $5(2.0)$ & $0(0.0)$ & \\
\hline Urinary incontinence* & & & 0.050 \\
\hline Yes & $43(17.3)$ & $15(30.0)$ & \\
\hline No & $205(82.7)$ & $35(70.0)$ & \\
\hline Visual impairment* & & & 0.004 \\
\hline Yes & $45(18.1)$ & $19(38.0)$ & \\
\hline No & $203(81.9)$ & $31(62.0)$ & \\
\hline Fall precaution at admission* & & & 0.221 \\
\hline Yes & $228(91.9)$ & $49(98.0)$ & \\
\hline No & $20(8.1)$ & $1(2.0)$ & \\
\hline Activity permitted before fall ${ }^{+}$ & & & 0.471 \\
\hline No restriction & $197(79.4)$ & $37(74.0)$ & \\
\hline RIB and toilet & $25(10.1)$ & $8(16.0)$ & \\
\hline CRIB (including restraint) & $26(10.5)$ & $5(10.0)$ & \\
\hline Body restraint used before fall* & & & 0.168 \\
\hline Yes & $19(7.7)$ & $7(14.0)$ & \\
\hline No & $229(92.3)$ & $43(86.0)$ & \\
\hline
\end{tabular}

${ }^{*}$ Data was analysed using Fisher's exact test. ${ }^{\dagger}$ Data was analysed using chi-square test. CRIB: complete rest in bed; RIB: rest in bed

increased flexion of the posture. The fall risk in elderly persons with dementia who have abnormal gait and balance is increased by three times compared to elderly persons with dementia who have normal gait. ${ }^{(16,17)}$ However, when such patients are hospitalised, their ambulatory aids are usually not with them. Even if the patients' ambulatory aids were brought with them to the hospital, the aids might not be easily accessible as, for safety purposes, the aids might be kept in a corner, which may be far from the patients' reach. When patients attempt to ambulate without their usual ambulatory aids, they are more prone to falls. Therefore, it is important for healthcare staff to remind patients or their relatives to bring along these ambulatory aids when the patients are hospitalised. Healthcare staff should also ensure that the ambulatory aids are placed close to the patients, and are readily and visibly accessible. This is especially important for patients with dementia, as they may not be cognitively competent to compensate for their gait disability.

Some risk factors known to be associated with night falls among elderly in- and outpatients include lower urinary tract symptoms (in men), urge incontinence, postural syncope and drinking water at night. ${ }^{(18)}$ Other associated features of falls that occur at night in hospitals include falls from the bed, dehydration, increasing age and being confused at the time of the fall. ${ }^{(19,20)}$ Another known risk factor for falls among elderly persons with dementia is visual impairment. Apart from visual acuity, depth perception and distant-edge-contrast sensitivity are important in maintaining balance, and detecting and avoiding environmental hazards. ${ }^{(21,22)}$ In our study, we noted that more fallers with dementia fell at night, compared to fallers without dementia. We also found that visual impairment and urinary incontinence were more common in fallers with dementia. The combination of the need to go to the toilet at night (i.e. in dim light) and visual impairment spells disaster for patients with cognitive impairment. Adequate lighting, especially in toilets and along the way to the toilet, are extremely important. For the visually impaired elderly with dementia, home safety measures are not only more cost-effective, they are also effective in reducing the incidence of falls. ${ }^{(23)}$ Regular screening for visual impairments may be useful in identifying visual impairments and offering treatment to the affected elderly with potentially reversible causes of visual impairment.

Urinary incontinence is a known risk factor for falls among elderly persons with dementia. ${ }^{(24)}$ Urinary incontinence is about four times more common among elderly persons with dementia 
Table III. Circumstances and consequences of falls.

\begin{tabular}{|c|c|c|c|}
\hline \multirow[t]{2}{*}{ Variable } & \multicolumn{2}{|c|}{ No. of patients (\%) } & \multirow[t]{2}{*}{ p-value } \\
\hline & Without dementia $(n=248)$ & With dementia $(n=50)$ & \\
\hline Occurrence of fall* (no. of days after hospitalisation) & $5.5(1-70)$ & $7.2(1-32)$ & 0.182 \\
\hline $\begin{array}{l}\text { Mental status at time of fall } \\
\text { Not confused } \\
\text { Confused }\end{array}$ & $\begin{array}{r}180(72.6) \\
68(27.4)\end{array}$ & $\begin{array}{c}3(6.0) \\
47(94.0)\end{array}$ & $<0.005$ \\
\hline $\begin{array}{l}\text { Period of fall } \\
\text { Morning shift } \\
\text { Afternoon shift } \\
\text { Night shift }\end{array}$ & $\begin{array}{r}152(61.3) \\
37(14.9) \\
59(23.8)\end{array}$ & $\begin{array}{l}19(38.0) \\
11(22.0) \\
20(40.0)\end{array}$ & $\begin{array}{l}0.009 \\
\text { NA } \\
0.020\end{array}$ \\
\hline $\begin{array}{l}\text { Location of fall } \\
\text { Bedside } \\
\text { On the way to the toilet } \\
\text { In the toilet } \\
\text { Others }\end{array}$ & $\begin{aligned} 179 & (72.2) \\
8 & (3.2) \\
46 & (18.5) \\
15 & (6.0)\end{aligned}$ & $\begin{aligned} 37 & (74.0) \\
& 2(4.0) \\
7 & (14.0) \\
4 & (8.0)\end{aligned}$ & 0.843 \\
\hline $\begin{array}{l}\text { Activity when fall occurred } \\
\text { Getting up from the bed } \\
\text { Getting up from the chair } \\
\text { Walking } \\
\text { Dressing } \\
\text { Transfer }\end{array}$ & $\begin{aligned} 158 & (63.7) \\
7 & (2.8) \\
63 & (25.4) \\
7 & (2.8) \\
13 & (5.2)\end{aligned}$ & $\begin{aligned} 32 & (64.0) \\
0 & (0.0) \\
16 & (32.0) \\
0 & (0.0) \\
2 & (4.0)\end{aligned}$ & 0.458 \\
\hline $\begin{array}{l}\text { Fall-related complication } \\
\text { Non-head injury } \\
\text { Head injury } \\
\text { Fracture } \\
\text { Intracranial haemorrhage } \\
\text { Others }\end{array}$ & $\begin{aligned} 183 & (73.8) \\
4 & (1.6) \\
8 & (3.2) \\
9 & (3.6) \\
44 & (17.7)\end{aligned}$ & $\begin{aligned} 38 & (76.0) \\
1 & (2.0) \\
3 & (6.0) \\
0 & (0.0) \\
8 & (16.0)\end{aligned}$ & 0.589 \\
\hline
\end{tabular}

Most data was analysed using chi-square test. ${ }^{*}$ Data is presented as mean (range), and was analysed using $t$-test. ${ }^{\dagger}$ Data was analysed using Fisher's exact test. NA: not available

than those without. Among elderly persons with dementia, the prevalence of urinary incontinence was found to range between $22 \%$ (community-dwelling) and $84 \%$ (residing in a nursing home). ${ }^{(25)}$ The causes of urinary incontinence among elderly persons with dementia include detrusor overactivity (due to the lack of central inhibition), functional incontinence with a combination of physical and cognitive impairments, lack of caregivers, impaired mobility, and psychological barriers associated with unwillingness to use the toilet. ${ }^{(26)}$ The management of urinary incontinence in the elderly includes pharmacological therapies and behavioural management, which includes timed voiding, prompted voiding, bladder training education for caregivers, physical therapy, environmental modifications and incontinence aids. ${ }^{(27)}$ Behavioural management of incontinence is known to be safe and effective. However, this is a labour-intensive approach that often requires a dedicated caregiver.

In many hospitals, many patients with dementia are nursed with diapers at night so as to reduce the frequency of toilet visits. This may not alleviate the situation as patients may not be used to urinating into diapers and still insist on getting up to urinate in the toilet. If patients with dementia are potted at fixed intervals (i.e. timed voiding) and prompted by nurses to void (i.e. prompted voiding) at night, they may be less likely to attempt to get up by themselves to go to the toilet. However, timed and prompted voiding are practised less frequently than diaper use due to constraints in manpower with regard to the nursing staff, particularly during the night shift. ${ }^{(28)}$ Compared to day shifts, staffing levels during night shifts are lower. A lower staffing level has been associated with a higher fall risk. ${ }^{(29)}$

In our study, reports of confusion could be due to underlying chronic confusion (dementia), acute confusion (delirium) or acute on chronic confusion. We found that the presence of confusion in our patients at the time of the fall was very high in those with dementia. Even for the fallers without a documented diagnosis of dementia in our study, about one third of them were confused at the time of the fall. This finding suggests a potentially large number of undiagnosed dementia/cognitive impairment in the group of fallers who were listed to not have dementia in the case notes. Another possible reason for the high incidence of confusion in fallers without dementia is the presence of acute medical conditions that may precipitate delirium, especially in the elderly. Furthermore, since delirium runs a fluctuating course and reassessment is seldom done, delirium is easily missed by medical, as well as nursing, staff if the patient was assessed during periods of lucidity. ${ }^{(30)}$ 
Hospital-associated adverse events are more common among elderly persons with delirium and cognitive impairment. ${ }^{(31)}$ Independent of age, sex, comorbid illness and baseline dementia, delirium has been shown to be associated with poor outcome. ${ }^{(32)}$ Several screening tools have been used in the assessment of acute confusion in the hospitalised elderly, and the choice of instrument used depends on the amount of time available and the discipline of the examiner. ${ }^{(33)}$ Early identification and treatment of acute confusion may help prevent falls in the hospitalised elderly. A high index of suspicion is required in the diagnosis of delirium. Unfortunately, screening for delirium is not routinely practised in most acute hospital settings.

In our study, fall precaution was initiated for most of the patients who eventually fell during their hospital stay. However, despite the fall precautions, a significant number of elderly patients still fell. This raises questions on the effectiveness and follow-through of the fall prevention measures used in hospitals. Tan et al reported restraint use to be associated with higher fall risk and increased severity of injuries among elderly inpatient fallers. ${ }^{(34)}$ Capezuti et al reported that the use of restraints was also not shown to be associated with a reduction in fall risk or injuries among nursing home residents, and discouraged the use of restraints to promote immobility in an effort to reduce falls. ${ }^{(35)}$ This is further supported in a later study where Capezuti et al found that the removal of restraints did not increase fall risk or subsequent injuries from falls in nursing home residents. ${ }^{(36)}$ In our study, we found that the use of restraints in our hospital for agitated or disruptive patients was not common. This may be due to better awareness about the consequences of restraint use in the frail elderly population.

In conclusion, compared to fallers without dementia, fallers with dementia were more likely to use ambulatory aids, have visual impairment, have urinary incontinence, and most significantly, be confused at the time of the fall. The diagnosis and management of delirium in such cases is a matter requiring urgency. Simple measures such as making ambulatory aids accessible to patients, ensuring there is adequate lighting at night, and timed voiding can reduce falls in hospitalised patients with dementia.

\section{REFERENCES}

1. Udén G. Inpatient accidents in hospitals. J Am Geriatr Soc 1985; 33:833-41.

2. Lord SR, Sherrington C, Menz HB,eds. Falls in Older People: Risk Factors and Strategies for Prevention. Cambridge: Cambridge University Press, 2001.

3. Oliver D, Britton M, Seed P, Martin FC, Hopper AH. Development and evaluation of evidence based assessment tool (STRATIFY) to predict which elderly inpatients will fall: case-control and cohort studies. BMJ 1997; 315:1049-53.

4. Hendrich A, Nyhuis A, Kippenbrock T, Soja ME. Hospital falls: development of a predictive model for clinical practice. Appl Nurs Res 1995; 8:129-39.

5. Tinetti ME, Speechley M, Ginter SF. Risk factors for falls among elderly persons living in the community. N Engl J Med 1988; 319:1701-7.

6. Morris JC, Rubin EH, Morris EJ, Mandel SA. Senile dementia of the Alzheimer's type: an important risk factor for serious falls. J Gerontol 1987; 42:412-7.

7. Oleske DM, Wilson RS, Bernard BA, Evans DA, Terman EW. Epidemiology of injury in people with Alzheimer's disease. J Am Geriatr Soc 1995; 43:741-6.
8. Buchner DM, Larson EB. Falls and fractures in patients with Alzheimer-type dementia. JAMA 1987; 257:1492-5.

9. Baker BR, Duckworth T, Wilkes E. Mental state and other prognostic factors in femoral fractures of the elderly. J R Coll Gen Pract 1978; 28:557-9.

10. Rubenstein LZ, Powers C. Falls and mobility problems: Potential quality indicators and literature review (the ACOVE Project). Santa Monica: RAND Corporation, 1999: 1-40.

11. Groves JE, Lavori PW, Rosenbaum JF. Accidental injuries of hospitalized patients. A prospective cohort study. Int J Technol Assess Health Care 1993; 9:139-44.

12. Udén G, Nilsson B. Hip fracture frequent in hospital. Acta Orthop Scand 1986; 57:428-30.

13. Stevenson B, Mills EM, Welin L, Beal KG. Falls risk factors in an acute-care setting: a retrospective study. Can J Nurs Res 1998; 30:97-111.

14. Chu LW, Pei CK, Chiu A, et al. Risk factors for falls in hospitalized older medical patients. J Gerontol A Biol Sci Med Sci 1999; 54:M38-43.

15. Tideiksaar R. Falling in Old Age: Prevention and Management. 2nd ed. New York: Springer, 1997.

16. Visser H. Gait and balance in senile dementia of Alzheimer's type. Age Ageing 1983; 12:296-301.

17. O'Keeffe ST, Kazeem H, Philpott RM, et al. Gait disturbance in Alzheimer's disease: a clinical study. Age Ageing 1996; 25:313-6.

18. Masui K, Yoshimura K, Sakura Y, et al. [Risk factors for falls and fractures at night in relation to lower urinary tract symptoms: a survey of outpatients and inpatients at a general hospital]. Hinyokika Kiyo 2011; 57:417-23. Japanese.

19. da Costa SG, Monteiro Dda R, Hemesath MP, Almeida Mde A. [Characterization of bed falls sustained by inpatients in a university hospital]. Rev Gaucha Enferm 2011; 32:676-81. Portuguese.

20. Von Renteln-Kruse W, Krause T. [Fall events in geriatric hospital in-patients Results of prospective recording over a 3 year period]. Z Gerontol Geriatr 2004; 37:9-14. German.

21. Ivers RQ, Cumming RG, Mitchell P, Attebo K. Visual impairment and falls in older adults: the Blue Mountains Eye Study. J Am Geriatr Soc 1998; 46:58-64.

22. Lord SR, Dayhew J. Visual risk factors for falls in older people. J Am Geriatr Soc 2001; 49:508-515.

23. Campbell AJ, Robertson MC, La Grow SJ, et al. Randomised controlled trial of prevention of falls in people aged $>$ or $=75$ with severe visual impairment: the VIP trial. BMJ 2005; 331:817.

24. Lee CY, Chen LK, Lo YK, et al. Urinary incontinence: an under-recognized risk factor for falls among elderly dementia patients. Neurourol Urodyn 2011; 30:1286-90.

25. Campbell AJ, Reinken J, McCosh L. Incontinence in the elderly: Prevalence and prognosis. Age Ageing 1985; 14:65-70.

26. Williams ME, Gaylord SA. Role of functional assessment in the evaluation of urinary incontinence. J Am Geriatr Soc 1990; 38:296-9.

27. Yap $\mathrm{P}$, Tan D. Urinary incontinence in dementia - a practical approach. Aust Fam Physician 2006; 35:237-41.

28. Faezah SK, Lim KH, Chuo AML. The 'Pampered' Generation in Free Paper Presentation at the Annual Scientific Meeting. Singapore: Changi General Hospital, 2002.

29. Staggs VS, Knight JE, Dunton N. Understanding unassisted falls: effects of nurse staffing level and nursing staff characteristics. J Nurs Care Qual 2012; 27:194-9.

30. Flagg B, Cox L, McDowell S, Mwose JM, Buelow JM. Nursing identification of delirium. Clin Nurse Spec 2010; 24:260-6.

31. Watkin L, Blanchard MR, Tookman A, Sampson EL. Prospective cohort study of adverse events in older people admitted to the acute general hospital: risk factors and the impact of dementia. Int J Geriatr Psychiatry 2012; 27:76-82.

32. Witlox J, Eurelings LS, de Jonghe JF, et al. Delirium in elderly patients and the risk of post discharge mortality, institutionalization, and dementia: a meta-analysis. JAMA 2010; 304:443-51.

33. Wong CL, Holroyd-Leduc J, Simel DL, Straus SE. Does this patient have delirium?: value of bedside instruments. JAMA 2010; 304:779-86.

34. Tan KM, Austin B, Shaughnassy M, et al. Falls in an acute hospital and their relationship to restraint use. Ir J Med Sci 2005; 174:28-31.

35. Capezuti E, Evans L, Strumpf N, Maislin G. Physical restraint use and falls in nursing home residents. J Am Geriatr Soc 1996; 44:627-33.

36. Capezuti E, Strumpf NE, Evans LK, Grisso JA, Maislin G. The relationship between physical restraint removal and falls and injuries among nursing home residents. J Gerontol A Biol Sci Med Sci 1998; 53:M47-52. 